REVISTA DE DERECHO UNED, NÚM. 8, 2011

\title{
FACTORES QUE PUEDEN INCIDIR EN EL PROCESO DE ATENCION A UN DROGODEPENDIENTE
}

\author{
Miguel Ángel Martín HeRnáNDEZ \\ Abogado. Diplomado en Criminología \\ Profesor tutor de Derecho Penal del Centro Asociado a la UNED \\ en Córdoba.
}

Resumen: Dentro de la Criminología, para algunos autores, la solución a la criminalidad estaría en una mayor punición. Para otros, por el contrario, la solución radicaría en la recuperación de la persona, ya que de esta forma, el binomio toxicómano-delincuente desaparecería. La imputabilidad tiene una íntima relación con las drogodependencias desde el punto de vista de la problemática legal. El ingreso en prisión, en el tema de las drogodependencias, quizás no sea la mejor solución pensando en un futuro, y como una forma de reinsertar al delincuente. El código penal español, prevé la sustitución de las penas privativas de libertad, por las medidas de seguridad previstas en los artículos 95, 96,97 y ss., y 102 y 104. En materia de aplicación de las medidas de seguridad, el código penal de 1995, es más restrictivo. Sin embargo la jurisprudencia viene admitiendo la sustitución de las penas privativas de libertad por las medidas de seguridad, en aquellos supuestos en los cuales se recoja en la sentencia la atenuante grave de drogadicción.

Palabras clave: Drogodependencias, prevención y control del delito, sustitución de las penas privativas de libertad por medidas de seguridad, criterios no jurisdiccionales del T.S., Artículo 368 del Código Penal.

Abstract: In the field of Criminology, part of the literature finds the best approach for the control and prevention of crime in more pe- 
nalties. Other scholars think that the solution lies in the recuperation of the person. From their point of view, this is a good approach that tries to make the pair addiction-crime disappear. The capacity of culpability is intimately related to addiction from a legal point of view. Prison is not the best way to deal with this problem if one wants to think in the future and rehabilitate the offender. The Spanish Criminal Code considers the substitution of imprisonment penalties with «medidas de seguridad» in articles 95, 96, 97 ss., 102 and 104. Thought the 1995 Criminal code is more restrictive in the issue, Judges and Tribunals do admit the substitution in cases of addiction.

Key words: Drug addiction, control and prevention of crime, substitution of imprisonment penalties with «medidas de seguridad», supreme court criteria, Criminal Code.

\section{CUESTIONES GENERALES}

Actualmente, dentro de la criminología hay varias corrientes dominantes. Para unas, la solución de la criminalidad hoy, estaría en una mayor punición, tanto de conductas, como en una elevación de las penas. De esa forma se conseguiría un mayor afianzamiento del Ordenamiento Jurídico, así como una mayor prevención general.

Para otros casos, sin embargo, la solución a la criminalidad actual, y concretamente en el tema de las toxicomanías, radicaría fundamentalmente en la recuperación de la persona, apareciendo en un alto porcentaje esa figura criminológica que se conforma bajo el binomio toxicómano-delincuente. Por tanto, si se consigue que esa persona supere su adicción a las drogas, lógicamente es de suponer que un alto porcentaje dejará de delinquir, y la recuperación de la persona será mucho más beneficiosa para la sociedad, puesto que, desparecerá el delincuente, y se reducirán los costos que ello supone para la sociedad. En este sentido comparto la tesis de que primero se es delincuente y posteriormente aparece el drogodependiente, si bien es cierto, que una vez que el delincuente a lo largo de su carrera criminal se convierte en toxicómano, el índice de delitos aumentara considerablemente.

La rehabilitación quiere decir simplemente que se programan una serie de esfuerzos que procurar preparar a los delincuentes para una vida socialmente más útil. Tanto la reeducación como la pena pueden ser desagradables (como los programas de drogas o alcohol en instituciones penales) y también ambos pueden centrarse en mo- 
derar la criminalidad de los delincuentes, pero sólo la rehabilitación implica un futuro socialmente más útil para el delincuente. ${ }^{1}$

Siguiendo a Otero LóPEZ², J.M., habría que diferenciar entre la delincuencia funcional, que es aquella en la que el adicto se encuentra obligado a delinquir para proporcionarse los medios económicos que le permitan comprar el producto, y la delincuencia inducida que se corresponde con la situación del individuo que tras consumir drogas, los efectos de las mismas, le aumentan la probabilidad de que se involucre en actividades delictivas.

\section{LA IMPUTABILIDAD: ALGUNOS ASPECTOS MÉDICO-LEGALES}

La imputabilidad es un concepto jurídico de base psicológica. De él dependen los de responsabilidad y culpabilidad. De que se reúnan las condiciones que lo constituyen, o de que estén ausentes, total o parcialmente, surgirán circunstancias modificadoras de la responsabilidad, recogidas en el Derecho positivo.

Imputar un acto, es atribuírselo a alguien, ponerlo en su cuenta, lo que jurídicamente equivale a la obligación de sufrir las consecuencias penales que, por la realización de un hecho delictivo, señala el ordenamiento legal.

El fundamento de la imputabilidad se encuentra en la afirmación de la libertad humana como criterio informante de la capacidad para responder de las acciones, libertad que puede perderse, o no haber existido nunca, si en el sujeto no se reúnen las circunstancias que la condicionan.

En la imputabilidad se da, pues, la coincidencia de un concepto jurídico y de uno psicológico.

La imputabilidad se refiere, por consiguiente, a un modo de ser del sujeto, a un determinado estado espiritual del mismo y a un conjunto de condiciones psíquicas existentes en él, en el momento de la ejecución de un hecho antijurídico, que le capacitan para responder del mismo ante el poder social.

\footnotetext{
${ }^{1}$ Ferdinand, T.N., «Modernas Tendencias en la Ciencia del Derecho Penal y en la Criminología «, en el Congreso Internacional Facultad de Derecho de la UNED, Madrid, 6 al 10 de noviembre de 2000.

${ }^{2}$ Otero Lopez, J.M., Delincuencia y Droga, Eudema. Madrid, 1994, págs. 39 a 40.
} 
Dichas condiciones, de acuerdo con la mayor parte de los tratadistas, consisten en: 1 . Un estado de madurez mínimo, fisiológico y psíquico. 2. Plena conciencia de los actos que se realizan. 3. Capacidad de voluntariedad. 4. Capacidad de libertad.

La inteligencia y la voluntad son, pues, las bases psicológicas de la imputabilidad penal. Cuando se hayan abolido, o estén gravemente perturbadas, la imputabilidad no existe. En ello coincide la mayoría de la doctrina española, que estima imputable a quien tiene capacidad de comprender lo ilícito del hecho o de obrar conforme a tal entendimiento.

En consecuencia, toda alteración mental que afecte estas funciones psicológicas es causa de no imputabilidad, único concepto que le está permitido manejar al médico en sus dictámenes periciales, por ser de raigambre psíquica, o mejor psicopatológica.

Según lo expuesto hasta ahora, la imputabilidad representa la capacidad para delinquir, ya que sin ella como requisito no puede existir un delito.

Algunos juristas afirman que la imputabilidad es una cuestión estrictamente jurídica, y que, como tal, los psiquiatras nada tienen que decir sobre ella. A nuestro entender, ello es un error. "Imputable» significa, en definitiva, que los actos realizados por una persona le son atribuibles como individuo normal de la mente; y las únicas personas, técnicamente capacitadas para determinar si una persona es o no normal de la mente, son los médicos psiquiatras, y, muy en especial, los psiquiatras forenses. Se trata de un concepto de contenido primordialmente médico con resultancia jurídica; es decir, un concepto, el de «imputabilidad», médico-legal. Este es, también, el criterio de la mayoría de psiquiatras y psicólogos que se han ocupado del problema: Gruhle, Aschaffenburg, Jauregg, Frank, Rasck Von Baeyer, y el jurista Kohlhaas.

Con respecto de la problemática psiquiátrico-legal de las drogodependencias ${ }^{3}$, cualquier tribunal sentenciador, es decir, los juristas tienen que pronunciarse sobre un concepto jurídico -la responsabilidad- en correspondencia con otro, médico-legal (y según algunos, también jurídico), la imputabilidad, tras valorar las posibles alteraciones del entendimiento y la voluntad (conceptos psicológicos incorporados al Derecho), debidas a alteraciones de las funciones psí-

${ }^{3}$ Marco Ribe, J., Martí Tusquets, J.L., Pons Bartrán, R., Psiquiatría Forense, Salvat Editores, Págs. 445-446 y ss. 
quicas -cuestión psiquiátrica, es decir, médica- en individuos afectos de drogodependencias -cuestión de toxicología, es decir, de Medicina.

Artículo 104. «1. En los supuestos de eximente incompleta en relación con los números $1^{\circ}, 2^{\circ}$ y $3^{\circ}$ del artículo 20 , el Juez o Tribunal podrá imponer, además de la pena correspondiente, las medidas previstas en los artículos 101, 102 y 103. No obstante, la medida de internamiento sólo será aplicable cuando la pena impuesta sea privativa de libertad y su duración no podrá exceder de la pena prevista por el Código para el delito. Para su aplicación se observará lo dispuesto en el artículo 99.

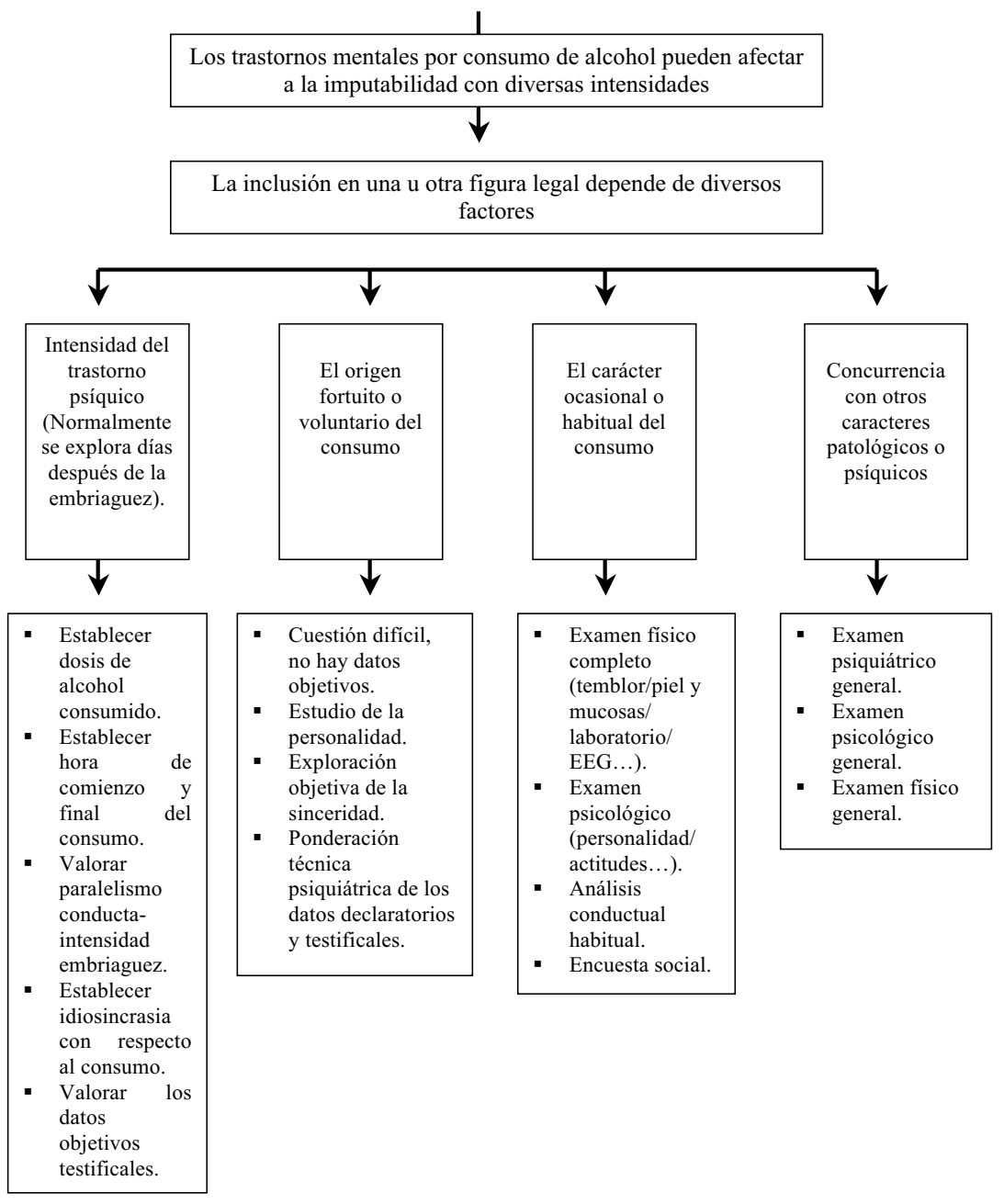

Fuente: Micó Catalán, F., Psiquiatría forense en esquemas, Colex, Madrid, 1996, pág. 139 
Dentro de las drogodependencias no podemos olvidarnos de la importancia del alcohol, que en medicina legal es muy considerable. La mayor parte de los autores consideran el alcohol como un importante factor criminógeno que enriquece el fichero judicial. Amén de las correspondientes alteraciones somáticas, el alcohol perturba las facultades de elección, juicio y raciocinio y facilita el salto a la agresividad ${ }^{4}$.

La ley no define al ebrio habitual, si bien podemos aproximarnos con tres criterios: hábito fuertemente arraigado, deterioro físico/psíquico e inestabilidad socio laboral y familiar.

La comisión de delitos durante un episodio de delirium tremens, alucinosis alcohólica, entran de lleno en el concepto de inimputabilidad al igual que las alteraciones de conducta en el síndrome de Korasakoff y encefalopatía de Wernicke. La intoxicación alcohólica aguda suele verse a la luz del trastorno mental transitorio siempre que no haya sido buscada de propósito para delinquir.

Para determinar si el consumo es progresivo y duradero, habrá que cuantificar las dosis y el tiempo de adicción. En este sentido nunca se deberá creer a un toxicómano bajo palabra y habrá que recabar otras fuentes de información y por supuesto detectar a los simuladores.

\section{LA REIMPUTABILIDAD ${ }^{5}$}

Gracias a los avances, en los últimos años, en el tratamiento de trastornos psíquicos -especialmente, la farmacoterapia de las psicosis-, puede darse el caso de que un individuo, afecto de un trastorno mental alienante, cometa un delito de motivación y contenido psicopatológicos, y del que, después, habiendo sido sometido a tratamiento cure; y superada su psicosis, realice un hecho punible, de motivación y contenido psicológicamente comprensible, del que será plenamente imputable. Esta posibilidad, debe tenerla siempre en cuenta el perito psiquiatra al valorar documentos médicos, de fecha anterior, que a menudo se le aportan en el curso de la peritación.

Así pues, será motivo de prueba, tanto para la acusación pública, como para la defensa, el mantenimiento de dichas posturas encontradas, pues tiene consecuencias legales importantes.

\footnotetext{
${ }^{4}$ Delgado Bueno, S., Esbec Rodríguez, E., Rodríguez Pulido, F., González De Rivera Y Revuelta, J. L., Psiquiatría Legal y Forense, editorial Colex, 1994.

${ }^{5}$ Martí Tusouets, J. L., Pons Bartrán, R., Psiquiatría Forense, Salvat Editores, pág. 9.
} 
Alternativas que ofrece el Código Penal de 1995 al Ingreso en Prisión. Sustitución de las Penas Privativas de Libertad por las Medidas de Seguridad previstas en los artículos 95, 96, 97 y siguientes y 102 y 104 del vigente Código Penal. Criterios Jurisprudenciales del Tribunal Supremo; Audiencias Provinciales y Juzgados de lo Penal.

Cuando una persona, como consecuencia de su adicción a las drogas ha sido condenada por un tribunal de justicia, lo inmediato es que esa sentencia se ejecute, y que se cumpla en los términos fijados en la misma. Lógicamente si el condenado está sometido a tratamiento de desintoxicación, será labor de su defensa intentar que ese proceso de desintoxicación no se vea interrumpido, por las consecuencias negativas que ello acarrearía. Sería dar un paso atrás. Por tanto habrá que intentar utilizar todos los recursos de que dispone nuestro ordenamiento jurídico, con tal finalidad.

Así pues y sentado lo anterior, analizaremos el tema de la sustitución de las penas privativas de libertad por las medidas de seguridad previstas en el Código Penal de 1995 y el tratamiento que le ha dado nuestro ordenamiento a lo largo del tiempo, a través de las distintas reformas legislativas operadas. Considero esencial fijar dos momentos cronológicamente hablando. Un primer momento sería, con anterioridad al Código Penal de 1995 y un segundo momento sería a partir de la aprobación de dicho Código Penal de 1995.

Por tanto una vez hecha esta aclaración y determinado el concepto de imputabilidad, convendría entrar en el fondo del asunto analizando los preceptos del Código Penal que nos darían cobertura o podrían darnos cobertura a la sustitución de las penas privativas de libertad por las medidas de seguridad previstas.

El Código Penal establece en su art. 96.2.2 $2^{\circ}$ que son medidas privativas de libertad «el internamiento en centro de deshabituación».

El artículo 99 del Código Penal dice que «en el caso de concurrencia de penas y medidas de seguridad privativas de libertad, el juez o tribunal ordenará el cumplimiento de la medida, que se abonará para el de la pena. Una vez alzada la medida de seguridad, el juez o tribunal podrá, si con la ejecución de la pena se pusiera en peligro los efectos conseguidos a través de aquella, suspender el cumplimiento del resto de la pena por un plazo no superior a la duración de la misma, o aplicar alguna de las medidas previstas en el artículo 96.3».

Art. 96: 3.Son medidas no privativas de libertad: $1^{\text {a }}$ La inhabilitación profesional. 2. ${ }^{a}$ La expulsión del territorio nacional de extranjeros no residentes legalmente en España. 3. ${ }^{a}$ La obligación de residir 
en un lugar determinado. 4. ${ }^{\text {a }}$ La prohibición de residir en el lugar o territorio que se designe. En este caso, el sujeto quedará obligado a declarar el domicilio que elija y los cambios que se produzcan. $5 .{ }^{a} \mathrm{La}$ prohibición de acudir a determinados lugares o territorios, espectáculos deportivos o culturales, o de visitar establecimientos de bebidas alcohólicas o de juego. $6{ }^{\mathrm{a}}{ }^{\mathrm{a}}$ La custodia familiar. El sometido a esta medida quedará sujeto al cuidado y vigilancia del familiar que se designe y que acepte la custodia, quien la ejercerá en relación con el Juez de Vigilancia Penitenciaria y sin menoscabo de las actividades escolares o laborales del custodiado. 7. ${ }^{a}$ La privación del derecho a conducir vehículos a motor y ciclomotores. 8. ${ }^{\text {a }}$ La privación del derecho a la tenencia y porte de armas. 9. ${ }^{a}$ La prohibición de aproximarse a la víctima, o a aquellos de sus familiares u otras personas que determine el Juez o Tribunal. 10. ${ }^{\text {a }}$ La prohibición de comunicarse con la víctima, o con aquellos de sus familiares u otras personas que determine el Juez o Tribunal. 11. ${ }^{\text {a }}$ La sumisión a tratamiento externo en centros médicos o establecimientos de carácter socio-sanitario. 12. ${ }^{a}$ El sometimiento a programas de tipo formativo, cultural, educativo, profesional, de educación sexual y otros similares.

El artículo 102 del Código Penal, dice que «a los exentos de responsabilidad penal conforme al número $2^{\circ}$ del artículo 20 se les aplicará, si fuere necesaria, la medida de internamiento en centro de deshabituación público, o privado debidamente acreditado u homologado, o cualquiera otra de las medidas previstas en el apartado 3 del artículo 96».

Artículo 102: "1. A los exentos de responsabilidad penal conforme al número 2 . $^{\circ}$ del artículo 20 se les aplicará, si fuere necesaria, la medida de internamiento en centro de deshabituación público, o privado debidamente acreditado u homologado, o cualquiera otra de las medidas previstas en el apartado 3 del artículo 96. El internamiento no podrá exceder del tiempo que habría durado la pena privativa de libertad, si el sujeto hubiere sido declarado responsable, y a tal efecto el Juez o Tribunal fijará ese límite máximo en la sentencia. 2. El sometido a esta medida no podrá abandonar el establecimiento sin autorización del Juez o Tribunal sentenciador de conformidad con lo previsto en el artículo 97 de este Código.

El internamiento, dice la ley no podrá exceder del tiempo que habría durado la pena privativa de libertad, si el sujeto hubiere sido declarado responsable. Téngase en cuenta que estamos hablando de personas exentas de responsabilidad.

El artículo 104 del Código Penal, que según mi criterio es el más problemático a los fines que analizamos, establece que el Juez podrá 
imponer (además de la pena correspondiente) las medidas previstas en los artículos 101, 102 y 103 del Código Penal, pero ello, sólo cuando la pena sea privativa de libertad.

Artículo 104. «1. En los supuestos de eximente incompleta en relación con los números $1^{\circ}, 2^{\circ}$ y $3^{\circ}$ del artículo 20 , el Juez o Tribunal podrá imponer, además de la pena correspondiente, las medidas previstas en los artículos 101, 102 y 103. No obstante, la medida de internamiento sólo será aplicable cuando la pena impuesta sea privativa de libertad y su duración no podrá exceder de la pena prevista por el Código para el delito. Para su aplicación se observará lo dispuesto en el artículo 99.

La medida de internamiento, solo será aplicable cuando la pena impuesta sea privativa de libertad, y su duración no podrá exceder de la prevista por el Código para el delito.

El artículo 101 se refiere a los que sean declarados exentos de responsabilidad criminal conforme al número $1^{\circ}$ del artículo 120; el artículo 102 a los exentos por el número $2^{\circ}$ del art. 20, y el artículo 103 para los declarados exentos conforme al número $3^{\circ}$ del artículo 120. Por su parte el art. 104 contempla los supuestos de eximente incompleta en relación con los números $1^{\circ}, 2^{\circ}$ y $3^{\circ}$ del artículo 20 , que de acuerdo con lo establecido en el art. $21.2^{\mathrm{a}}$ es circunstancia atenuante «la de actuar el culpable a causa de una grave adicción a las sustancias mencionadas en el número $2^{\circ}$ del artículo anterior».

Es un artículo, a mi entender problemático en cuanto a su aplicación- como después analizando los criterios jurisprudenciales aclararemos-, toda vez que entendemos alude, en su contenido, a la eximente incompleta, pero no alude, ni hace referencia en su texto literal, a la atenuante de drogadicción.

El artículo 87 del Código Penal establece que, aun cuando no concurran las condiciones $1^{\mathrm{a}}$ y $2^{\mathrm{a}}$ previstas en el artículo $81^{6}$, «el juez o tribunal, con audiencia de las partes, podrá acordar la suspensión

${ }^{6}$ Artículo 81 del código penal «Serán condiciones necesarias para dejar en suspenso la ejecución de la pena, las siguientes: $1 .{ }^{a}$ Que el condenado haya delinquido por primera vez. A tal efecto no se tendrán en cuenta las anteriores condenas por delitos imprudentes ni los antecedentes penales que hayan sido cancelados, o debieran serlo, con arreglo a lo dispuesto es el artículo 136 de este Código. 2. ${ }^{a}$ Que la pena o penas impuestas, o la suma de las impuestas, no sea superior a dos años, sin incluir en tal cómputo la derivada del impago de la multa. 3. ${ }^{a}$ Que se hayan satisfecho las responsabilidades civiles que se hubieren originado, salvo que el Juez o Tribunal sentenciador, después de oír a los interesados y al Ministerio Fiscal, declare la imposibilidad total o parcial de que el condenado haga frente a las mismas». 
de la ejecución de las penas privativas de libertad no superiores a cinco años de los penados que hubiesen cometido el hecho delictivo a causa de su dependencia de las sustancias señaladas en el número $2^{\circ}$ del artículo 20, siempre que se certifique suficientemente, por centro o servicio público o privado debidamente acreditado u homologado, que el condenado se encuentra deshabituado o sometido a tratamiento para tal fin en el momento de decidir sobre la suspensión. El juez o tribunal solicitará en todo caso informe del Médico Forense sobre los extremos anteriores ${ }^{7} »$.

Por tanto, concurren dos elementos importantes a tener en cuenta, y que son: en primer lugar que el quantum de la condena puede superar los dos años, y en segundo lugar que no tiene que ser la primera vez que delinca. No obstante, se establece, extremo muy importante, que el Juez o Tribunal necesitará, en todo caso, recabar informe del médico forense sobre los extremos anteriores.

Un vez analizados los artículos o preceptos del Código Penal que hacen alusión a los supuestos de aplicación de las medidas de seguridad, así como, a las eximentes y atenuantes que inciden o hacen referencia al tema de la drogadicción, cabría volver nuevamente a esos dos momentos a los que hemos hecho alusión anteriormente, y que son, uno, con anterioridad al Código Penal de 1995 y otro a partir de la vigencia del Código Penal del 1995.

Son dos momentos totalmente diferenciados, y en tal sentido habría que decir que el Código Penal nuevo, el de 1995, en materia de aplicación de las medidas de seguridad, es mucho más restrictivo que el Código Penal anterior al de 1995, así por ejemplo, cabe la posibilidad de aplicar las medidas de seguridad a las que hemos hecho alusión anteriormente, en aquellos supuestos en los cuales esté recogida en la sentencia la existencia de una eximente completa o incompleta, pero siempre y cuando esté declarado así en la sentencia. Sin embargo, no será posible la aplicación de la medida de seguridad en aquellos supuestos en los cuales en la sentencia solamente esté declarada la concurrencia de una atenuante grave de drogadicción. En

${ }^{7}$ El art. 20 del código penal, establece que: «Están exentos de responsabilidad criminal: ... $2^{\circ}$. El que al tiempo de cometer la infracción penal se halle en estado de intoxicación plena por el consumo de bebidas alcohólicas, drogas tóxicas, estupefacientes, sustancias psicotrópicas u otra que produzcan efectos análogos, siempre que no haya sido buscado con el propósito de cometerla o no se hubiese previsto o debido prever su comisión, o se halle bajo la influencia de un síndrome de abstinencia, a causa de su dependencia de tales sustancias, que le impida comprender la ilicitud del hecho o actuar conforme a esa comprensión» . 
tal sentido, los criterios de la Fiscalía son acordes con el criterio restrictivo del Código Penal de 1995, en el sentido, de que no procede la aplicación de las medidas de seguridad en aquellos casos en que concurra solamente una atenuante grave de drogadicción, aunque esté recogido en la sentencia, y que sin embargo, si cabe la aplicación de una medida de seguridad en aquellos supuestos de eximente completa o incompleta, pero siempre y cuando que esté recogido y declarado así en la sentencia.

Lógicamente a la luz de esta interpretación hay que concluir que el Código Penal de 1995 es mucho más restrictivo y tiene muchas más limitaciones a la hora de aplicar las medidas de seguridad que el Código Penal anterior.

Esto evidentemente ha creado una serie de problemas en la aplicación práctica, puesto que, en un primer momento ha supuesto un retroceso dentro de los recursos existentes para facilitar el proceso de reinserción y de recuperación de aquellas personas con problemas relacionados con la drogadicción. Por tanto, ha habido que recurrir a las resoluciones de los Tribunales de justicia para ver que establece la jurisprudencia en los supuestos que acabamos de mencionar.

En tal sentido, dejar sentado que serán los Juzgados de lo Penal y las Audiencias Provinciales respectivas las que van, en definitiva, a resolver sobre todas estas cuestiones de la aplicación o no de las medidas de seguridad como alternativa al cumplimiento de la pena, en definitiva, serán estos tribunales los que van a resolver.

Lógicamente tras la aprobación del nuevo Código penal, los recursos procesales se han ido sucediendo desde el momento en el cual se han ido denegando por los tribunales de justicia la aplicación de las medidas de seguridad en aquellos supuestos en los cuales no concurre una eximente completa o incompleta, sino que concurre solamente una atenuante grave de drogadicción.

\section{LA JURISPRUDENCIA}

Habría que analizar dos momentos, cronológicamente hablando, y en concordancia con los dos momentos a los que hemos hecho alusión anteriormente. Un primer momento referido a la jurisprudencia aplicable con anterioridad a la entrada en vigor del Código Penal de 1995; y un segundo momento a partir de la entrada en vigor del actual Código Penal de 1995. 
Con anterioridad al actual Código Penal, y con respecto de la sustitución de la pena privativa de libertad por las medidas de seguridad previstas en el Código Penal, el criterio seguido era, que tanto para los supuestos de eximente completa, incompleta, así como para los de atenuante de drogadicción, y siempre y cuando que tal circunstancia estuviese declarada y recogida en la sentencia, el criterio era mantener la posibilidad de dicha sustitución de la pena privativa de libertad por la medida de seguridad. La jurisprudencia era unánime en el sentido de aplicar tal criterio.

A raíz de la entrada en vigor del Código Penal vigente de 1995, el criterio en un primer momento es, que siempre que esté declarada y recogida en la sentencia la circunstancia de la drogadicción como eximente completa o incompleta se sigue manteniendo la posibilidad de sustituir la pena privativa de libertad por la medida de seguridad. Sin embargo, en aquellos supuestos de atenuante grave de drogadicción, incluso aunque esté recogida y declarada en la sentencia, ha venido siendo criterio unánime de los Juzgados de lo Penal, así como, de los informes de Fiscalía, la no procedencia de la aplicación de la sustitución de la pena privativa de libertad por la medida de seguridad.

El criterio utilizado y la argumentación han sido simple y sencillamente porque el Código Penal no lo tiene previsto, ni lo tiene recogido en el texto de la ley. Así, hacer alusión al contenido del artículo del 104 Código Penal, no tiene sentido, ya que el mismo se refiere al artículo 21.1, es decir, a la eximente incompleta en relación con el artículo 20.2 de drogadicción, y sin embargo, por el tenor literal de su contenido no hace alusión ni directa, ni indirectamente, a la atenuante grave de drogadicción. Por tal motivo, los Tribunales de Justicia, con el apoyo en sus informes de la Fiscalía, venían rechazando la sustitución de la pena privativa de libertad por las medidas de seguridad.

Evidentemente, como hemos dicho, surge una situación de retroceso a este respecto en comparación con el Código Penal anterior al de 1995, así, los recursos contra estas denegaciones de sustitución de la pena privativa de libertad por la medida de seguridad comenzaron a sucederse y las Audiencias Provinciales, que es donde finalizan prácticamente todos estos recursos, empiezan a resolver sobre la aplicación o no de las medidas de seguridad, teniendo en cuenta las limitaciones que establece el Código Penal actual con respecto al Código Penal anterior. Así la jurisprudencia empieza a dictar sentencias, las cuales tienen como común denominador la argumentación siguiente. Normalmente, toda la jurisprudencia al respecto, co- 
mienza resolviendo cuestiones donde el Ministerio Fiscal se ha opuesto a la sustitución de la pena privativa de libertad que haya correspondido en cada momento, por las medidas de seguridad previstas en los artículos 101 y siguientes del vigente Código Penal, fundamentando la desestimación el Ministerio Fiscal de la aplicación de la medida de seguridad, por el hecho de que la misma, solo está prevista cuando en sentencia se haya apreciado una eximente completa o incompleta y que en el procedimiento penal de turno, solo se había aplicado la atenuante grave de drogadicción del artículo 21.2 del mismo cuerpo legal.

Por tanto, el tema planteado a debate, relativo a la aplicabilidad de las previsiones del artículo 99 y 104 del Código Penal, a los supuestos de atenuante grave de drogadicción en relación con el artículo 20.1 es el tema de debate central de todas las sentencias que seguidamente iremos citando, y que han sido resueltos por las Salas correspondientes de las Audiencias Provinciales en un sentido afirmativo a la aplicación de la sustitución de la pena privativa de libertad por la medida de seguridad, para también aquellos supuestos en los cuales se recoja en la sentencia la atenuante grave de drogadicción.

\section{ULTIMAS CONSIDERACIONES}

Será en la interpretación jurisprudencial del nuevo Código Penal del 95 cuando los Tribunales de Justicia planteen en sus sentencias que ante análogos presupuestos, refiriéndose a los del Código Penal derogado, análogas consecuencias, refiriéndose al Código Penal nuevo, y fundamentando dicha jurisprudencia que debe de aplicarse en los tres supuestos y no solamente en los supuestos de eximente completa o incompleta, puesto que, estamos en presencia de una delincuencia funcional, que tiene un alto consumo diario, en algunos caso pueden darse hasta 500 dosis diarias, y que es una figura criminológica, la del drogodependiente, que se caracteriza, entre otras, por ser multireincidente, donde debe de primar fundamentalmente, refiriéndose al artículo 25 de la Constitución Española, a los criterios de reeducación, reinserción y resocialización y con una tendencia a la no interrupción dentro del proceso de desintoxicación de la persona consumidora de sustancias tóxicas que desee abandonar dicho consumo, es decir, favorecer con todos los medios legales ala alcance la interrupción del proceso de vertebración personal en aquellos individuos que han optado por el abandono en el consumo de las drogas. 
Es competencia y función de los Juzgados y Tribunales velar por el cumplimiento del proceso de desintoxicación y la aceptación y sometimiento a dicho proceso por parte de las personas que solicitan la sustitución de la pena por la medida de seguridad, estudiando muy detenidamente el «iter» de desintoxicación de la persona afectada.

No quisiera terminar sin hacer una alusión también relacionada con el proceso de desintoxicación del drogodependiente, pero en este caso dentro del sistema penitenciario, en aras de buscar cualquier tipo de recurso admitido en derecho para conseguir la no interrupción del proceso de desintoxicación; en definitiva para procurar su rehabilitación y reinserción social conforme postula el artículo 25 de la Constitución Española.

Quisiera recoger por lo alarmante que en el tema que nos ocupa son, las conclusiones a las que han llegado los expertos en derecho penitenciario de los colegios de abogados andaluces ${ }^{8}$, reunidos en la localidad Onubense de Punta Umbría en un encuentro en el que han analizado el sistema carcelario andaluz y han puesto al descubierto irregularidades manifiestas e incumplimientos graves de la legislación.

Los más perjudicados por estas violaciones de derechos son los reclusos drogodependientes, cuya reinserción social es poco menos que imposible, a juicio del colectivo de letrados. La insuficiencia de medios es la causa fundamental de que no se apliquen en las cárceles de la comunidad varios artículos del Reglamento Penitenciario. Entre las irregularidades que han denunciado los letrados andaluces destaca la «arbitrariedad» con la que los centros penitenciarios deniegan los permisos a los reclusos drogodependientes, por el mero hecho de serlo. Según este colectivo profesional, en las cárceles andaluzas se equipara la drogadicción con la mala conducta a la hora de decidir sobre la concesión de un permiso.

En concreto, dice el informe de conclusiones del encuentro, es habitual utilizar el criterio de «drogodependencia no superada» para denegar los permisos, empleado con total arbitrariedad, ya que -dicen los expertos -se usa tanto cuando el interno se encuentra en tratamiento como cuando no lo está. A todo ello hay que sumar que, también sistemáticamente, las direcciones de los centros penitenciarios rechazan las peticiones de los internos para someterse a controles de analítica, la "prueba más objetiva y sencilla» para demostrar si ha consumido sustancias estupefacientes.

\footnotetext{
${ }^{8}$ Fuente: Periódico El mundo de Andalucía, 4 de junio de 2006.
} 
El documento de conclusiones, señala que no se aplica, por ejemplo, el artículo 117, que permita las salidas terapéuticas en segundo grado, o el adelantamiento de la libertad condicional que contempla el 91.2, además del artículo 182, que permite el cumplimiento de la condena para un recluso drogadicto en un centro de tratamiento extra penitenciario en régimen de tercer grado.

Así, destacan, no sólo es difícil, casi imposible una efectiva reinserción social, ya que, encima, priman en los centros repartidos por la comunidad los castigos a los tratamientos.

Dicen los abogados especializados en asistencia penitenciaria que es hora de dar un giro a esta política, ofreciendo alternativas de manera que se permita que aquellas personas que reciban el alta terapéutica no tengan que regresar a prisión para cumplir el resto de su condena, sin que puedan continuar con su tratamiento con un régimen ambulatorio. Esta solución no sólo redundaría, alegan estos especialistas, en una mayor facilidad para que los presos adictos a la droga se incorporen a la sociedad. Asimismo, conllevaría una descongestión de las comunidades terapéuticas -un recurso muy demandado -y, de paso, las propias cárceles.

En definitiva, estamos en presencia de un tema muy complicado y delicado, donde queda mucho por andar y por legislar, si lo que realmente se pretende es resocializar al drogodependiente y rescatarlo del mundo de las drogas.

Aspectos criminológicos y criterios jurisprudenciales de los tribunales superiores de justicia, audiencia nacional, y sala de lo contencioso administrativo, con respecto a ley orgánica 1/92, de 21 de febrero de protección de la seguridad ciudadana (B.O.E. $n^{\circ} 46$ de 22 de febrero de 1992).

Tal y como se establece en la Exposición de Motivos de la citada Ley Orgánica 1/92 de 21 de Febrero, la protección de la seguridad ciudadana y el ejercicio de las libertades públicas constituyen un binomio inseparable, y ambos conceptos son requisitos básicos de la convivencia en una sociedad democrática.

La Constitución Española, por otra parte, establece una atribución genérica de competencia al Estado en materia de seguridad pública (artículo 149.1.29a) y, específicamente atribuye a las Fuerzas y Cuerpos de Seguridad, bajo la dependencia del Gobierno, la tarea de proteger el libre ejercicio de los derechos y libertades, y garantizar la seguridad ciudadana (artículo 104.1), afectando en su regulación al ejercicio de algunos derechos fundamentales, como el derecho a la li- 
bertad, a la libre circulación por el territorio nacional, y a entrar y salir libremente de España o al derecho de reunión.

El capítulo cuatro de la citada ley establece un régimen sancionador que permite el cumplimiento de las finalidades de la ley y de las correspondientes garantías constitucionales. Tipifica las infracciones contra la seguridad ciudadana, haciendo la graduación entre infracciones muy graves, graves e infracciones leves; comprendiéndose específicamente entre las infracciones graves el consumo en lugares públicos y la tenencia ilícita de drogas tóxicas o sustancias estupefacientes, las cuales podrán ser sancionadas, además con la suspensión del permiso de conducir de vehículos de motor hasta 3 meses, y con la retirada de permiso o licencia de armas. Atendiendo al fin resocializador y no exclusivamente retributivo de la sanción, se regula en la presente ley, para estos supuestos, la posibilidad de suspensión de las sanciones en los casos en que el infractor se someta a un tratamiento de deshabituación en un centro o servicio debidamente acreditado. Continúa diciendo la Exposición de Motivos que asimismo este capítulo cuarto determina las sanciones que cabe imponer y las autoridades competentes para ello, estableciendo un procedimiento sancionador con las debidas garantías. Por otra parte se dispone la obligación del Ministerio Fiscal de remitir testimonio de las sentencias absolutorias o autos de sobreseimiento y archivo cuando los hechos no sean constitutivos de infracción penal, por si pudieran ser constitutivos de infracción administrativa de las previstas en esta ley.

Por tanto, vamos a analizar el aspecto administrativo sancionador del consumo de sustancias tóxicas, y lo vamos a analizar con el estudio fundamentalmente de los artículos 23 apartado i, 25.1 y 28 de la Ley 1/92, para posteriormente entrar a analizar cuáles son los criterios jurisprudenciales de los Tribunales Superiores de Justicia de las Comunidades Autónomas y de la Sala de lo Contencioso Administrativo de la Audiencia Nacional.

El artículo 23 de la citada ley está ubicado dentro del capítulo cuarto, como hemos dicho anteriormente, que recoge el régimen sancionador y en su sección primera se refiere a las infracciones. Dicho artículo 23 establece a los efectos de la presente ley, que constituyen infracciones graves, y enumera una serie de apartados centrándonos fundamentalmente en el apartado «i», el cual dice: - «la tolerancia del consumo ilegal o el tráfico de drogas tóxicas, estupefacientes o sustancias psicotrópicas en locales o establecimientos 
públicos, o la falta de diligencia en orden a impedirlos por parte de los propietarios, administradores o encargados de los mismos.-»

Por tanto, vemos que este artículo 23 hace alusión tanto a la tolerancia en el consumo, a la tolerancia en el tráfico de estupefacientes o drogas tóxicas o psicotrópicas e incluso hace alusión, llegando aún más lejos, a la falta de diligencia por parte de los propietarios, administradores o encargados de dichos locales, a impedir tal consumo.

Por otra parte, el artículo 25 de la citada ley establece en su párrafo primero que constituye infracciones a la seguridad ciudadana el consumo en lugares, vías, establecimientos o transportes públicos, así como, la tenencia ilícita, aunque no estuviera destinada al tráfico, de drogas tóxicas estupefacientes, o sustancias psicotrópicas, siempre que no constituya infracción penal, así como, el abandono en los sitios mencionados de útiles o instrumentos utilizados para el consumo.

El artículo 25 en su apartado segundo dispone que las sanciones impuestas por estas infracciones podrán suspenderse si el infractor se somete a un tratamiento de deshabituación en un centro o servicio debidamente acreditado, en la forma y por el tiempo que reglamentariamente se determine. Por tanto, como después veremos a través de las sentencias de los Tribunales de Justicia, este artículo 25 en sus apartados primero y segundo sanciona tres bloques fundamentalmente, por un lado el consumo tanto en lugares públicos como en vías públicas, establecimientos y transportes públicos, en segundo lugar la tenencia ilícita aunque no estuviese destinada o abocada al consumo y siempre que no constituya infracción penal, y un tercer bloque que sanciona también el abandono, en los citados lugares, de los útiles o instrumentos para el consumo.

El artículo 28 de la Ley 1/92 regula las sanciones, y en su apartado primero establece que las infracciones determinadas de acuerdo con lo dispuesto en la sección anterior podrán ser corregidas por las autoridades competentes con una o más de las sanciones siguientes, y así en el apartado a) establece multa de 5.000.001 de pesetas $(30.050,61 €)$ a 100.000 .000 de pesetas $(601.012 .10 €)$ para las infracciones muy graves.

De 50.001 pesetas $(300,51 €)$ a 5.000 .000 de pesetas $(30.050,61 €)$, para infracciones graves.

De hasta 50.000 de pesetas $(300,51 €)$ para infracciones leves.

En el mismo citado artículo 28, en su apartado 1p, se establece también la clausura de las fábricas, locales o establecimientos, desde 
seis meses y un día hasta 2 años por infracciones muy graves y hasta seis meses por infracciones graves, en el ámbito de las materias reguladas en el capítulo dos de esta ley, de igual forma, para los casos graves de reincidencia la suspensión y la clausura a la que se refieren los dos apartados anteriores, podrán ser de dos años y un día hasta 6 años para infracciones muy graves, y hasta 2 años por infracciones graves.

El apartado 2 del artículo 28 establece que las infracciones previstas en el artículo 25 podrán ser sancionadas, además, con la suspensión del permiso de conducir vehículos de motor hasta 3 meses, y con la retirada del permiso o licencia de armas, procediéndose desde luego a la incautación de las drogas tóxicas, estupefacientes o sustancias psicotrópicas.

El artículo 27 de la citada ley regula las infracciones administrativas contempladas en la presente ley, prescribirán a los 3 meses, al año y a los dos años e haberse cometido según se trate de infracciones leves, graves o muy graves respectivamente.

\section{JURISPRUDENCIA}

Hay que comenzar, al respecto de lo que acabamos de analizar, con una sentencia de la Audiencia Nacional, Sala de lo Contencioso Administrativo, de 12 de Junio de 1998.

Los hechos motivadores a los que alude la sentencia son los siguientes: a las 22:35 horas del día 9 de Diciembre de 1995, la Guardia Civil procede a realizar un reconocimiento en establecimiento público donde tenía conocimiento de existir consumo de drogas, e interviene a dos clientes e identifica una pequeña "china» de una sustancia que resultó ser hachís, de unos 3 gramos de peso cada una. Apareciendo en el local 18 gramos de hachís y 13 colillas liadas con esta sustancia, pudiendo apreciar la Guardia Civil el olor peculiar que dan al ambiente el consumo de estas sustancias.

El artículo 23 de la Ley 1/1992, de 21 de Febrero sobre Protección de la Seguridad Ciudadana, de aplicación a este caso, establece que constituyen infracciones graves:

La tolerancia del consumo ilegal o el tráfico drogas tóxicas, estupefacientes o sustancias psicotrópicas en locales o establecimientos públicos o la falta de diligencia en orden a impedirlos por parte de los propietarios, administradores o encargados de los mismos. 
Continúa después la sentencia diciendo en el supuesto de autos, del expediente sancionador, se deduce una evidente tolerancia o falta de diligencia por parte del titular del establecimiento para impedir el consumo de una sustancia estupefaciente de tráfico ilícito, como es el hachís, incluido en la lista I y II del Convenio de 1961, y ello, dice la sentencia, se pone de manifiesto con dos clientes que llevan 3 gramos de esta sustancia y apareciendo en el suelo, al ser arrojado por sus tenedores, 18 gramos y 13 colillas, lo que indica que en ese momento se estaba consumiendo, corroborado por la apreciación de la Guardia Civil al hacer constar en su atestado el olor peculiar que dan al ambiente el consumo de estas sustancias, y sin embargo el titular no hizo nada por impedirlo, es más, la profusión y generalización del consumo evidencia una clara tolerancia o permisividad de este, por tanto, la sentencia entiende que ha existido consumo y además que se ha tolerado, por lo que concurren los supuestos necesarios exigidos por el artículo 23.i) de la Ley 1/92, sancionando la clausura del establecimiento por el período de 1 año por infracción de la Ley de Seguridad Ciudadana.

Otra sentencia también de interés es la dictada por la Audiencia Nacional, Sala de lo Contencioso Administrativo, Sección Octava, de fecha 27 de Abril de 2000.

Dicha sentencia confirma la sentencia dictada por el Juzgado de lo Contencioso Administrativo, que imponía una multa de 500.000 pesetas y clausura del establecimiento público por un período de 6 meses por la comisión grave tipificada en el artículo 23. i) de la Ley de Protección de Seguridad Ciudadana, relativa al tolerancia del consumo ilegal o tráfico de drogas tóxicas, estupefacientes o sustancias psicotrópicas en los locales o establecimientos públicos, o la falta de diligencia en orden a impedirlos por parte de los propietarios, administradores o encargados de los mismos. En el supuesto de autos y objeto del correspondiente recurso, mediante denuncia practicada por la Guardia Civil en intervención practicada en un pub, se recogieron en el suelo 37 colillas de hachís (6,45 gramos), dos trozos de dicha sustancia (2,49 gramos), una jeringuilla de insulina vacía, y todo ello, según dice la fuerza actuante, en un ámbito de fuerte olor a hachís, y procediendo varios clientes a arrojar cigarrillos al suelo. En el recurso, alega el recurrente que ignoraba por completo que en su local se consumieran dichas sustancias, por lo que entiende no se puede atribuir al titular de un establecimiento la condición de garante de todo lo que ocurra en su interior y además cuando, como decía el titular del establecimiento, ha colocado un cartel en el que prohíbe a los clientes el consumo de drogas. 
Argumenta la sentencia que estudiadas las circunstancias concurrentes, y en concreto el intenso olor a hachís, que se desprende de los informes y declaraciones, que había en el establecimiento, y el gran número de colillas semi-apagadas de hachís (37 colillas), ninguna duda hay que estaba tolerando el consumo desustancias estupefacientes y que estaba omitiendo la diligencia necesaria para evitar dicho consumo, por lo que, la Audiencia Nacional, Sala de lo Contencioso, desestima el recurso administrativo interpuesto y confirma la resolución dictada por ser ajustada a derecho.

Sentencia del Tribunal Superior de Justicia de Andalucía, Sala de Contencioso Administrativo de Sevilla, Sección Cuarta, de fecha 26 de Enero de 2000, en el presente recurso los agentes de la Guardia Civil que se encontraban en el interior de un establecimiento, denuncian de como advirtieron el hecho de que cuatro personas estaban consumiendo cigarrillos de tabaco mezclados con resina de hachís en las proximidades de las pistas de baile, según se precisa en el informe que se evacuó tras el Pliego de Descargos. El recurrente articula en su defensa que el locales encontraba lleno de clientes (alrededor de 500 personas), lo que imposibilitaba un control que impidiera el consumo de sustancias estupefacientes en el local, y existiendo, además, carteles prohibiendo la tenencia y consumo de sustancias prohibidas por la ley.

Argumenta la sentencia que lo que se tipifica como infracción grave en el artículo 23 i), de la Ley $1 / 92$ es la tolerancia del consumo ilegal o tráfico de drogas tóxicas, estupefacientes o sustancias psicotrópicas en locales o establecimientos públicos, o la falta de diligencia en orden a impedirlos, supuesto este último en el que encaja la conducta omisiva del demandante, pues los hechos hacen referencia al consumo, en lugar fácilmente visible cual es en los alrededores de la pista de baile, de una sustancia que, por sus características, pude advertirse con igual facilidad, sin que por parte del actor de adoptar medida alguna efectiva en orden a impedirlo, salvo la meramente formal e insuficiente de la colocación de carteles con la advertencia sobre la prohibición de consumo de drogas o sustancias prohibidas. De aquí que pueda hablarse de la falta de diligencia que justifica la imposición de la sanción.

Por tanto, el recurso interpuesto por la actora fue desestimado confirmando la sentencia dictada por el Juzgado a quo.

Sentencia del Tribunal superior de Justicia de Castilla y León, Sala de lo Contencioso Administrativo de Valladolid, de fecha 2 Diciembre de 2002. 
El recurso se fundamenta en una infracción prevista en el artículo 25.1 de la Ley Orgánica 1/92 de 21 de Febrero sobre la Protección de la Seguridad Ciudadana por consumo de drogas (un cigarrillo de hachís) en lugar público.

Se impuso como consecuencia dicha acción una multa de 50.005 pesetas, al considerar responsable de una infracción prevista en el artículo 25.1 de la Ley Orgánica 1/92, por consumir un cigarrillo de hachís en un lugar público, concretamente en la vía pública.

La tesis de la actora y recurrente en el presente recurso, fue que no había constancia del consumo de hachís por su parte, pues aun aceptando que tuviera en sus manos un cigarrillo de esa sustancia no se probó por la Administración que efectivamente lo estuviera consumiendo, lo que a su juicio habría hecho necesario que se le ofreciere y se practicara, bien un análisis de la saliva, bien un análisis de sangre. En igual sentido, afirma la demandante que el cigarrillo que le fue decomisado no coincide en modo alguno con el que le fue entregado para su análisis al Ministerio de Sanidad, por lo que, concluye, ha sido sancionada por sostener en la vía pública un cigarrillo cuya composición es una incógnita.

Contesta o rebate la sentencia en el sentido siguiente, en lo que respecta al primer alegato, debe reseñarse que el consumo mencionado viene respaldado por la denuncia obrante en las actuaciones que fue ratificadas por sus autores, es decir por las fuerzas actuantes, y que le guste o no a la demandante y recurrente constituye base suficiente para adoptar la resolución sancionadora con arreglo a lo dispuesto en el artículo 37 de la Ley Orgánica 1/92.

«En los procedimientos sancionadores que se instruyan en la materia objeto de la presente ley, las informaciones aportadas por los agentes de la autoridad que hubieren presenciado los hechos, previa ratificación en el caso de haber sido negados por los inculpados, constituirán base suficiente para adoptar la resolución que proceda, salvo prueba en contrario y sin perjuicio de que aquellos deban aportar al expediente todos los elementos probatorios disponibles.»

En cualquier caso, y aparte de que en esa denuncia y en esa ratificación se asegura que la recurrente se encontraba consumiendo un cigarrillo de hachís a los 2:45 de la noche en la vía pública, se juzga oportuno poner de relieve que el tipo aplicado contempla no sólo el consumo sino la tenencia ilícita de drogas, dato que se destaca porque en su alegato insistía la actora en que ella sólo sostenía en la mano un cigarrillo que no era suya, lo que en último término hace in- 
necesario su análisis, que la misma se refería para poder justificar su no consumo de la droga, análisis que debe quedar claro ella no llegó a proponer en ningún momento. Concluye la sentencia desestimando el presente recurso y confirmando la sentencia dictada por el Juzgado a quo.

Sentencia del Tribunal Superior de Justicia de la Región de Murcia, Sala de lo Contencioso Administrativo, Sección Segunda, de fecha 23 de Mayo de 2001, dice la sentencia que el artículo 25.1 de la Ley Orgánica 1/92, afirma que constituyen infracciones graves a la seguridad ciudadana el consumo en lugares, vías, establecimientos o transportes públicos, así como la tenencia ilícita, aunque no estuviese destinada al tráfico, de drogas tóxicas, estupefacientes o sustancias psicotrópicas, siempre que no constituya infracción penal, así como, el abandono en los lugares mencionados de útiles o instrumentos utilizados para su consumo.

Mantiene la sentencia, siguiendo el criterio mayoritario de los Tribunales Superiores de Justicia como el de Andalucía- Granada (sentencia 5 de Mayo de 1997) y el de Navarra (en sentencias de 14 de Septiembre de 1999 y 9 de Diciembre de 1999), entiende que la posesión de las citadas sustancias en un vehículo privado estacionado o circulante por la vía pública, cual es el caso de esta sentencia, puede subsumirse en dicho precepto legal, entendiendo que se trata de una tenencia ilícita en vía pública, lo cual viene apoyado por el artículo 28.2 de la Ley Orgánica 1/92, cuando dice que las infracciones previstas en el artículo 25 podrán ser sancionadas además con la suspensión de conducir vehículos de motor hasta 3 meses.

Asimismo continua diciendo la sentencia que hay que tener en cuenta que el concepto de tenencia ilícita a que se refiere este precepto, según la jurisprudencia, no es contrario a las diligencias del principio de legalidad del artículo 25.1 de la Constitución Española, tanto en lo que se refiere al rango de la regla delimitadora del delito, como en lo relativo a la configuración misma de la conducta infractora. La ley no remite a un reglamento la determinación de lo que se haya de entender por tenencia ilícita, sin embargo es preciso acudir a otras reglas legales como la Ley 17/1967 de 8 de abril (Estupefacientes), para identificar que es tenencia ilícita- artículo 22 de dicha leyy determinar, por contraste con ella, la tenencia ilícita sancionable (Sentencia del Tribunal Constitucional de 18 de Noviembre de 1993 y Sentencia del Tribunal supremo de 28 de Septiembre de 1998), precepto este último en el que se relacionan específicamente los usos permitidos (industriales, terapéuticos, científicos y docentes 
autorizados con arreglo a la presente ley) para, en consecuencia considerar prohibidos cualesquiera otros, pues según el texto legal no se permitirán otros usos de los estupefaciente, así como la tenencia, siempre que no esté enderezada a los concretos usos relatados.

Finalmente la sentencia pone de manifiesto que toda resolución sancionadora tiene que ser motivada tal y como exige con carácter general el artículo 138.1 de LRJAP/PAC 30/92 de 26 de Noviembre. En este sentido la Sentencia del Tribunal Supremo de 11 de Julio de 1992 dice que corresponde a la actividad jurisdiccional no solo la facultad de subsumir la conducta del infractor en un determinado tipo legal, sino también adecuar la sanción al hecho cometido, se trata de la aplicación de criterios jurídicos plasmados en la norma escrita a través de principios informadores del ordenamiento jurídico sancionador como lo son el principio de congruencia, y proporcionalidad entre la sanción y la infracción.

El caso que se enjuiciaba en esta sentencia se le impuso al actor una sanción en el grado máximo, concretamente 50.000 pesetas, previsto para las infracciones del artículo 28.1a) de la Ley Orgánica $1 / 92$, pero sin expresar de forma motivada todas las circunstancias tenidas en cuenta para ello.

Por tal motivo por los argumentos que acabábamos de reseñar el recurso se estimó únicamente anulando el acto impugnado exclusivamente en lo que se refiere a la cuantía de la sanción de multa impuesta que se rebajaba de 50.000 a 25.000 pesetas.

Sentencia del Tribunal Superior de Justicia de la Comunidad Valenciana, Sala de lo Contencioso Administrativo, Sección Tercera, de fecha 11 de Febrero de 2001, dice la sentencia que consta en el expediente administrativo que este fue iniciado en virtud de atestado de la Guardia Civil manifestando, que con motivo de una operación especial contra la delincuencia y hallándose en un cruce de carreteras determinado, se procedió a identificar al conductor de un vehículo que resultó ser el actual demandante, a quien se le ocuparon 3 trozos pequeños de una sustancia compacta de color marrón que llevaba en el bolsillo del pantalón, envuelta en papel celofán, en un análisis posterior, efectuado en el laboratorio de la Dirección Territorial de Sanidad, esa sustancia resultó ser hachís en cantidad de 0,54 gramos. Por tanto, continúa diciendo la sentencia, que los hechos se ajustan a la norma aplicada, pues el artículo 25.1 de dicha Ley Orgánica sanciona dicha tenencia ilícita de droga sin exigir su consumo ostensible en lugares públicos, tipificando con ello una infracción de simple actividad consistente en la posesión o tenencia de 
tales sustancias, siempre que sea ilegal o ilícita y con independencia del ánimo o propósito del tenedor, en este caso, concluye la sentencia, quedó probado que la sustancia que portaba el sancionado era hachís, calificada como ilegal por sus efectos psicotrópicos y estupefacientes y sin que obste de que se trate de una pequeña cantidad y también por faltar la prescripción facultativa para su consumo.

Y finalmente citaremos una Sentencia del Tribunal Superior de Justicia de Galicia, Sala de lo Contencioso Administrativo, Sección $2^{\mathrm{a}}$, de fecha 25 de Abril de 2002, se trata de una sentencia absolutoria, y en cuanto al fondo del asunto dice la misma que ha de convenirse en que los hechos imputados a la recurrente, cuya realidad no se discute, no son constitutivos de la infracción por cuya comisión es sancionada. Es obvio que la conducta atribuida a la actora de entre las que enumera el artículo 25.1 de la LOSG, es la tenencia ilícita de una sustancia estupefaciente, heroína. Se basa la apreciación de dicha tenencia en que en el papel de aluminio que le fue ocupado se detectaron restos de la referida sustancia, aunque tan escasos que no se concretó su cantidad en el documento que refleja la práctica del correspondiente análisis. La ínfima cantidad de la sustancia detectada impide considerar cometida la infracción en la modalidad antes indicada, pues la tenencia ha de ser de algo que tenga cuantitativamente la entidad necesaria para que pueda ser consumido, ya que, de lo contrario se estaría sancionando una conducta anterior de consumo sin constancia de que se hubiese producido en algunos de los lugares que enumera el precepto.

Por tanto y por tales razones la sentencia fue absolutoria.

El artículo 369.5 del actual código penal español, prevé la agravación por notoria importancia en los delitos contra la salud pública. Cuantía de droga necesaria para apreciar la notoria importancia. Aspectos criminológicos y criterios del tribunal supremo. El pequeño traficante.

En el artículo 368 del Código Penal español, establece que: Los que ejecuten actos de cultivo, elaboración o tráfico, o de otro modo promuevan, favorezcan o faciliten el consumo ilegal de drogas tóxicas, estupefacientes o sustancias psicotrópicas, o las posean con aquellos fines, serán castigados con las penas de prisión de tres a seis años y multa del tanto al triplo del valor de la droga objeto del delito si se tratare de sustancias o productos que causen grave daño a la salud, y de prisión de uno a tres años y multa del tanto al duplo en los demás casos. 
En el artículo $369.1 .5^{\mathrm{a}}$ se agrava la pena al tratarse de una cantidad de notoria importancia.

En el artículo 376 permite bajar la pena en uno o dos grados tratándose de un drogodependiente si la cantidad no fuese de notoria importancia o extrema gravedad.

En el artículo 377 para la determinación de la cuantía de las multas se tendrá en cuenta el precio final del producto o la recompensa o ganancia que pudiese obtener el reo.

Así podemos ver, según el siguiente cuadro, cuáles han sido los precios y purezas de las sustancias psicoactivas en nuestro país, dentro del mercado ilícito entre 1998 y $2008^{9}$.

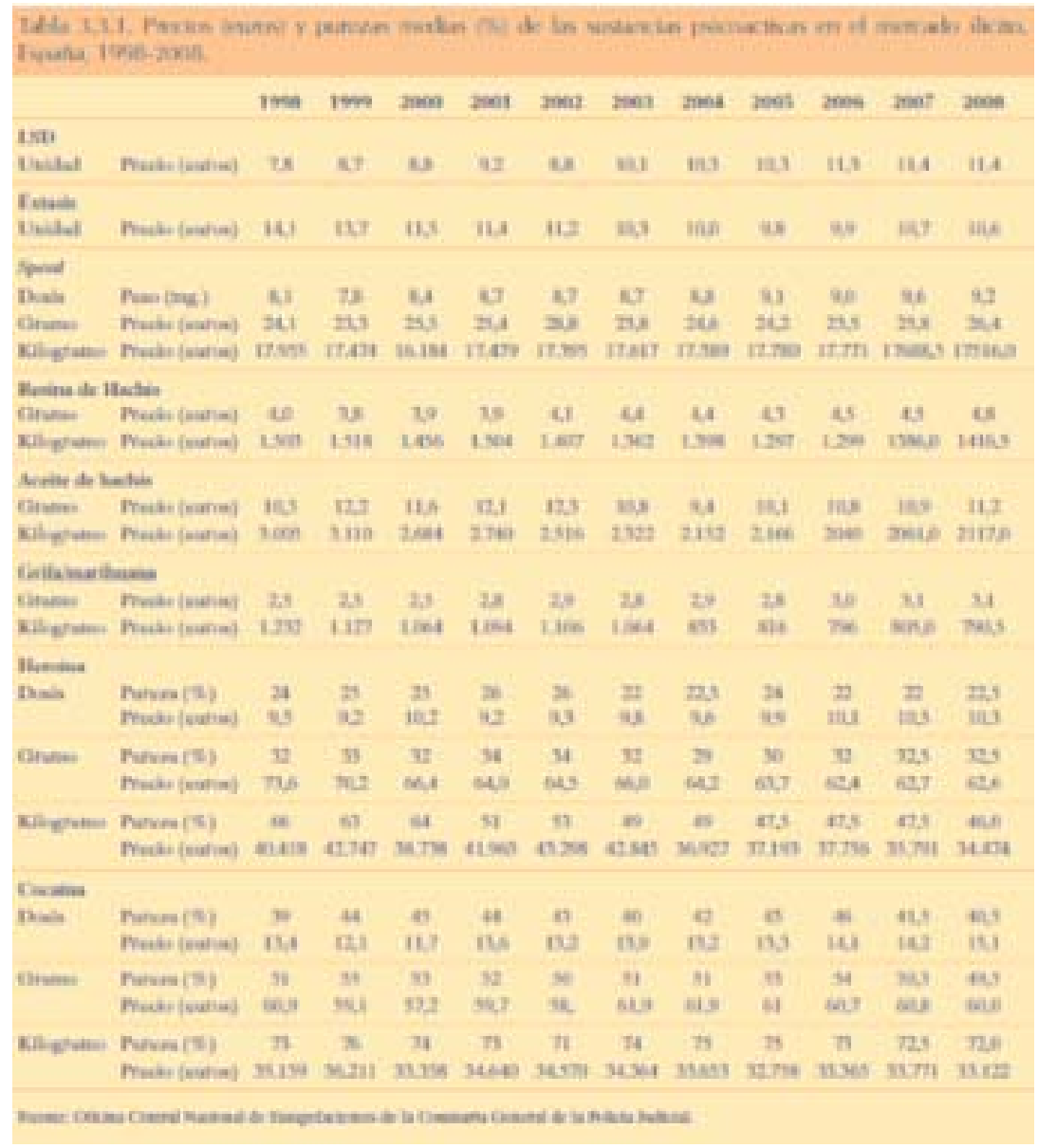

${ }^{9}$ Fuente: Oficina Central Nacional de Estupefacientes de la Comisaría General de la Policía Judicial 
En este cuadro, podemos percibir, los precios medios de las drogas en el mercado ilícito en nuestro país en el periodo 1996-2008 ${ }^{10,11}$.

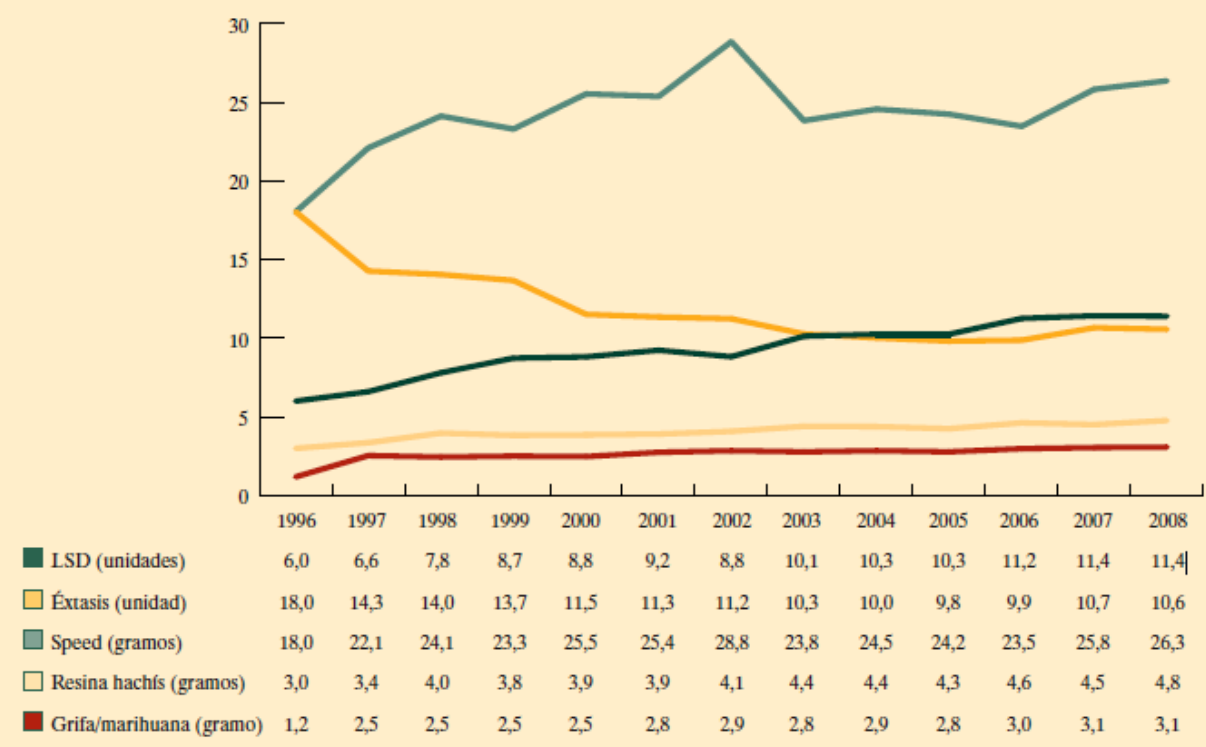

Fuente: Ministerio del Interior. Oficina Central Nacional de Estupefacientes de la Comisaria General de Polića Judicial.

${ }^{10}$ Fuente: Ministerio del Interior. Oficina Central Nacional de Estupefacientes de la Comisaría General de Policía Judicial.

${ }^{11}$ Fuente: Ministerio del Interior. Oficina Central Nacional de Estupefacientes de la Comisaría General de Policía Judicial. 
El Tribunal Supremo adopta acuerdos en los cuales fija su postura jurisprudencial de igual forma que la Fiscalía lleva a cabo sus circulares.

En uno de estos acuerdos fijan la cuantía de droga aprendida que es necesaria para que se aprecie la agravación por notoria importancia en los delitos contra la salud pública previstos en el artículo 369.5 de Código Penal.

El Tribunal Supremo, ante la situación de los correos de la droga que venían viendo agravadas sus penas de manera desproporcionada, ha optado por aumentar esa cuantía ${ }^{12}$. Por acuerdo del Pleno de la Sala Segunda del Tribunal Supremo, de 19 de Octubre de 2001, se ha modificado el anterior criterio adoptado también por el Pleno de la misma Sala de fecha 5 de Febrero de 1999, donde se había acordado mantener los criterios vigentes hasta la fecha sobre las cantidades determinantes de la agravación por notoria importancia en los delitos contra la salud pública (artículo 369.5 del Código Penal).

El tipo básico del artículo 368 del Código Penal castiga con penas de 3 a 6 años de prisión a los que cultiven, elaboren, trafiquen o posean drogas tóxicas y estupefacientes. Pero si la cantidad es de «notoria importancia» se aplica el artículo 369.5 que agrava las penas, imponiendo la pena superior en grado a la señalada en el artículo anterior, y multa del tanto al cuádruplo.

$\mathrm{Al}$ elevarse ahora la cantidad de notoria importancia, el pequeño traficante pude ser castigado con una pena de 3 a 6 años.

Por tanto, la necesidad de adaptar las penas de los «correos» de la droga al principio de proporcionalidad, es un problema que ya ha sido puesto de manifiesto en innumerables ocasiones, como pone de manifiesto Fernando Bejarano Guerra, entra las que debe destacarse el Informe del Consejo General del Poder Judicial sobre los Problemas Derivados de la Aplicación del Nuevo Código Penal (Ley Orgánica 2/95 de 23 de Noviembre). En ese sentido en la página 101 de dicho informe se concluía que las penas para los correos de la droga que trasportaban cantidades no muy elevadas de la misma, a veces en su propio organismo, parecían excesivas.

No cabe duda de la aplicación de todos estos criterios a aquellos procedimientos que estén pendientes de sentencia, sin embargo, nada se dice al respecto de la adaptación de las condenas firmes, a aquellos

12 Bejarano Guerra, F., Nuevos criterios de Tribunal Supremo: Se aumenta la cuantía de droga aprehendida, Penal Diciembre 2001/Enero 2002, pág. 64. 
supuestos en que los reos vienen cumpliendo penas privativas de libertad acordes con la jurisprudencia dictada hasta esa fecha.

Saliendo al paso de este problema la Fiscalía General del Estado en su Circular número 3/96 y analizando el problema en cuestión, fijó que cuando el Tribunal Supremo modifica sus criterios sobre algún extremo en la interpretación de la ley penal, la citada rectificación no alcanza a las sentencias ya firmes.

En definitiva con este acuerdo del Tribunal Supremo, lo que se pretendía, no era otra cosa que elevar la cantidad de droga de notoria importancia, a efectos de poder atenuar la penalidad sobre el pequeño traficante, que antes( hasta el 23 de diciembre de 2010) podía ser castigado con una pena de 9 a trece años de prisión (Art. 369.3) en cuanto sobrepasaba ese límite mínimo, y actualmente, y con el vigente código penal, al haber elevado dichas cantidades de notoria importancia, podrá ser castigado con una pena de 3 a 6 años (Art.368).

El Tribunal Supremo en su nuevo criterio jurisprudencial establece la aplicación de la agravante específica a partir de las 500 dosis, referidas al consumo diario. Consumo diario que aparece actualizado en el informe del Instituto Nacional de Toxicología de 18 de Octubre de 2001.

A la concreción de la agravante de cantidad de notoria importancia, se mantendrá el criterio seguido por el Tribunal Supremo de tener exclusivamente en cuenta la sustancia base o tóxica, esto es, reducido a pureza, con la salvedad de hachís y sus derivados.

El porcentaje de riqueza de la sustancia es importante a efecto de determinar si existe o no delito, se utiliza para saber si es capaz de causar riesgos para la salud y supone la proporción del principio activo contenido en ella ${ }^{13}$.

Si bien es cierto, como hemos dicho anteriormente, que no procederá la revisión de las sentencias firmes y que solo será de aplicación a aquellos procedimientos en marcha o pendientes de dictar sentencia, para aquellos otros procedimientos en los cuales exista sentencia firme y los condenados estén cumpliendo condena, no obs-

${ }^{13}$ En la sentencia 413/2007 de 9 de mayo, el Tribunal establece una interpretación a favor del reo aceptando que en los análisis de las sustancias respecto del pesaje y determinación de la pureza existe un margen de error de un 5\%, en este caso la sustancia intervenida era de 303,55 grs. de heroína de la cual apreciando un simple error del 1,2\% sale una cantidad de 299,91 grs., con lo cual ya no sería cantidad de notoria importancia. 
tante para estos supuestos, habrá de informarse favorablemente la solicitud de indulto al objeto de que las condenas se corresponda a lo que resulta del presente acuerdo adoptado por el Tribunal Supremo.

Para facilitar la aplicación de la agravante específica según lo acordado por el Tribunal Supremo, reflejamos a continuación un cuadro acorde con el remitido al Tribunal Supremo por el Instituto Nacional de Toxicología, y en el que se determinaban las cantidades que resultaban de las 500 dosis, atendiendo el consumo diario estimado y de acuerdo con lo estimado por el informe emitido por dicho Instituto.

\begin{tabular}{|c|c|c|c|c|}
\hline \multicolumn{5}{|c|}{ Cantidades de droga de "notoria importancia" } \\
\hline Sustancia & Denominaci & & Fiscalización & Cantidad \\
\hline \multicolumn{5}{|c|}{ Opiáceos } \\
\hline Hervina & - Caballo & & Lista I y IV C.U. 1961 & $300 \mathrm{gs}$ \\
\hline Morina & $\begin{array}{l}\text { Clonuro morfic } \\
\text { - Cloruro morfic } \\
\text { - Morfina braun } \\
\text { - Morfina serra } \\
\text { - MSI continus } \\
\text { - Sevedrol } \\
\text { - Skenan }\end{array}$ & $\begin{array}{l}\text { andromaco } \\
\text { broun }\end{array}$ & $\begin{array}{l}\text { Lista I } \\
\text { Convencion Unica } 1961\end{array}$ & $1.000 \mathrm{grs}$. \\
\hline Metadona & Metasedin & & Lista I C.U. 1961 & $120 \mathrm{grs}$. \\
\hline Buprenafing & - Buprex Prefin & & Lista III Cormenia de Vena & $1,2 \mathrm{grs}$ \\
\hline Dentropropaxileno & - Darvon Depra & & Lista il C.U. 1961 & 300 grs. \\
\hline Pentarocina & $\begin{array}{l}\text { - Pentazocina Fi } \\
\text { - Sosegon }\end{array}$ & & $\begin{array}{l}\text { Lista III } \\
\text { Converio de Viena }\end{array}$ & $180 \mathrm{gs}$ \\
\hline Fentenilo & $\begin{array}{l}\text { - Durogesic } \\
\text { Fentanest }\end{array}$ & & Lista IC.U. 1961 & $50 \mathrm{mg}$ \\
\hline Dinidrocodeina & - Contugesic & & Lista IIC.U. 1961 & $180 \mathrm{gs}$ \\
\hline Levoaceti-Metadol & - Laam Orlam & & Lista ICU 1961 & $90 \mathrm{gs}$ \\
\hline Petidina & - Meperidina & - Dolantina & Lista I Cu. 1961 & $150 \mathrm{gs}$ \\
\hline Tramadol & $\begin{array}{l}\text { - Adolanta } \\
\text { - fradonal } \\
\text { - Iramadol }\end{array}$ & $\begin{array}{l}\text { Tianes } \\
\text { - Iralgijol } \\
\text { - Asta Medica }\end{array}$ & & 200 grs \\
\hline \multicolumn{5}{|c|}{ Derivados de la cocaina } \\
\hline Llarhudrato de cocalina & $\begin{array}{l}\text { - Nieve } \\
\text { - Spedoall }\end{array}$ & - Pentico & Lista ICU. 1961 & 750 grs \\
\hline \multicolumn{5}{|c|}{ Derivados del cannabis } \\
\hline Marituana & $\begin{array}{l}\text { - Hiertha } \\
\text { - Costo }\end{array}$ & $\begin{array}{l}\text { - Grita } \\
\text { - María }\end{array}$ & $\begin{array}{l}\text { Iista I y IV C. II 1961 } \\
\text { Lista II C.U. } 1971\end{array}$ & $10 \mathrm{~kg}$ \\
\hline Hachis & Chocolate & & $\begin{array}{l}\text { Lista I y IV C.U. } 1961 \\
\text { Lista II C.U. } 1971\end{array}$ & $2.5 \mathrm{~kg}$ \\
\hline Acelhe de Hachis & Chocolate & & $\begin{array}{l}\text { Lista I y IV C.U. } 1961 \\
\text { Lista II C.U. } 1971\end{array}$ & 300 grs \\
\hline ISD & - Tripi Acido & & ListalCU. 1971 & $300 \mathrm{mg}$ \\
\hline \multicolumn{5}{|c|}{ Derivados de la Feniletilanina } \\
\hline Sulfeto de anfetamina & $\begin{array}{l}\text { Anfeta } \\
\text { - Centramina }\end{array}$ & - Spedd & Lsta II C. Viena1971 & 90 grs \\
\hline Anlepramone & - Delgamer & & Lista IV C. Vena 1971 & 75 grs \\
\hline Clobenzorex & Finedal & & Anero Rn 2R2977 & $45 \mathrm{grs}$ \\
\hline Fenproporex & $\begin{array}{l}\text { Antiobes } \\
\text { - Grasmin } \\
\end{array}$ & $\begin{array}{l}- \text { Rectard } \\
\text { - Tegisec }\end{array}$ & Lista IV C. Viene 1971 & $175 \mathrm{gs}$ \\
\hline D. Metanfetamina & -Speed & - Tripi (en ocasiones) & Lista II C. Kena 1971 & $30 \mathrm{grs}$ \\
\hline \multicolumn{5}{|c|}{ Hipnouticus y sedantes } \\
\hline Alprazolam & $\begin{array}{l}\text { - Aprazolam ef } \\
\text { - Aprazolam ge } \\
\text { - Aprazolam m } \\
\text { - Irarkimszin }\end{array}$ & $\begin{array}{l}\text { rmes } \\
\text { minis } \\
\text { rck }\end{array}$ & Lista N C, Viena 1971 & 5 grs \\
\hline Iriazdam & - Hakcion & & Lista IV C. Viena 1971 & $15 \mathrm{grs}$ \\
\hline Flunitrazepan & Rohipno & & Lista III C. Viena 1971 & 5 grs \\
\hline Lorazepam & $\begin{array}{l}\text { Donix } \\
\text { - Orfidal } \\
\text { - Placinoral }\end{array}$ & $\begin{array}{l}\text { - Idalprem } \\
\text { - Lorazepom medical } \\
\text { - Sedizepan }\end{array}$ & Lista IV C. Kena 1971 & $75 \mathrm{gs}$ \\
\hline Clorazepato di potásico & - Nansius & -Transilium & Lista IV C. Viena 1971 & $75 \mathrm{grs}$ \\
\hline \multicolumn{5}{|c|}{ Drogas de sintesis } \\
\hline MOA & Plidora del amo & & Lista IC. Kiena 1971 & $240 \mathrm{~g} / \mathrm{s}$ \\
\hline MDMAA & Extasis & & Lista I C. Viena 1971 & $240 \mathrm{grs}$ \\
\hline MOEA & Eva & & Lista I C. Viena 1971 & $240 \mathrm{grs}$ \\
\hline
\end{tabular}


Así la Sentencia del Tribunal Supremo, Sala Segunda de lo Penal, de fecha 5 de Julio de 2004. En el presente caso el Juzgado de Instrucción número 1 de Bilbao incoó sumario por un delito contra la salud pública, posteriormente la Sección Primera de la Audiencia Provincial de Vizcaya dictó sentencia condenándolos, como autores de un delito contra la salud pública con la concurrencia de la agravante de notoria importancia del artículo 369.3 del Código Penal, a 9 años de prisión y multa.

Contra dicha sentencia se interpuso Recurso de Casación, entre otros motivos, por infracción del Ley al amparo del artículo 849.1 de la LECrim, denunciando la infracción por indebida aplicación del artículo 369.3 del Código Penal. A su vez, se aducía dicho recurso en aplicación del acuerdo del Pleno no Jurisdiccional de la Sala Segunda del Tribunal Supremo de fecha 19 de Octubre de 2001.

El Tribunal Supremo aplicando los nuevos criterios en cuanto a la aplicación de la agravante de notoria importancia casó la sentencia y se dictó una nueva en la que acogiendo los criterios establecidos se sustituyó la pena impuesta en la sentencia de instancia anulada de 9 años de prisión y multa de $24.040 €$, por la procedente de 3 años de prisión y multa de $6.000 €$.

No obstante, en los últimos años, se ha ido imponiendo una doctrina en la Sala $2^{\text {a }}$ de nuestro TS de absolver a los acusados de tráfico de drogas cuando se trataba de venta de una papelina o dosis individual de sustancia estupefaciente, es decir, lo que vulgarmente se conoce como «trapicheo» $\mathrm{o}$ «menudeo».

Esta teoría se ha venido aplicando cuando dichos actos eran mínimos, atendiendo a la cantidad de droga vendida, basándose para ello en una doctrina de origen alemán llamada de «insignificancia» o de «lesividad». Sin embargo, dependiendo del órgano enjuiciador, se condenaba o absolvía en casos iguales, lo que ocasionaba la vulneración del principio de seguridad jurídica.

Dicha doctrina tuvo su precedente inmediato en la STS de 28 de Octubre de 1996 en la que se absolvía al acusado que había transmitido 0,6 gramos de heroína considerando que por su insignificancia quedaba por debajo de los umbrales mínimos de intervención del derecho punitivo al no generar riesgo alguno para el bien jurídico protegido, concluyendo la misma estableciendo que «el ámbito objetivo del tipo no puede ampliarse de forma desmesurada.»

Este principio de insignificancia se ha aplicado de manera ocasional al tráfico de drogas, aunque la última jurisprudencia dice que 
no es posible su aplicación porque al tratarse de un delito grave, el peligro abstracto ya es suficiente para justificar su intervención (Recurso de Amparo 563/2007). Solo se aplica de manera excepcional y restrictiva cuando la «absoluta nimiedad» de la sustancia ya no constituya una droga tóxica o estupefaciente sino un producto inocuo. Ejemplos de aplicación el principio de insignificancia por la jurisprudencia del Tribunal Supremo:

0,05 grs. heroína (STS 12 septiembre 1994)

0,06 grs. heroína (STS 28 octubre 1996)

0,02 grs. heroína (STS 22 enero 1997)

0,10 grs. cocaína (STS 22 septiembre 2000)

0,02 grs. cocaína (STS 11 diciembre 2000)

compartir dosis de un tratamiento de metadona (STS 18 julio 2001) 
